\title{
Economic Principles of Forest Transportation, (Ekonomicheskie Osnovy Trans- porta Lesa)
}

By V. 1. Garuzov (in Russian). Lesnaya Promishlennost (Forest Industry) Publishing House. Moscow 1965. 298 p.

Although not described as a textbook, the work was probably written to be used for teaching at university level. The book starts with a useful analysis of the forestry industry and the role of transportation. It reiterates the fact that wood processing industries in Russia are located far from the forest stands and that while "twenty-five percent of wood taken out is firewood, often not used, the country suffers from a lack of industrial timber." In the course of the discussion useful statistics are supplied on labor productivity, on the share of various forms of transportation in carrying forest industry products, on the time element and costs involved in construction of various types of necessary transportation, and so on. In discussing the principles underlying the planning of transportation (Chapt. II) two points are brought out clearly: the desirability of building large processing units in areas with large forest stands (northern European Russia, West and East Siberia and the Far East) is advocated, and the advisability of developing road transportation as against using rivers is stressed. In every case it is underlined that alternative modes of transport should be studied carefully for every project under construction, bearing in mind the reserves, their state, the technical and technological aspects, the historical and the natural conditions, the exploitation indexes and the economic considerations. The book provides mathematical formulae and graphs used to arrive at rational choices. Special efforts are made to demonstrate the relationship between transport costs and such factors as timber stands, permissible cut, the capacities of plants, turnover and speed of travel on the roads, the cost of road building, distances, relief, terminal points etc. A few specific examples of transport costs are given to illustrate theoretical formulations.

Separate chapters are devoted to the influence of natural conditions on the costs of construction, to problems of operating forest transportation systems and to the choice of technical parameters. The last two chapters deal with the choice of alternative transportation systems and the comparison of such on the basis of technical characteristics through the use of cost indexes and through estimates of capital investments, allowing also for time factor. The book has its shortcomings, the main one being that the forest resources are treated rather unrealistically. Yet to a student of Russia's forest industry this is a valuable contribution and if possible should be translated in full to make its contents available to non-Russian speaking students of the subject.

J. SOLECKI 